\title{
Nuclear Innovation Workshops
}

\section{September 2015}

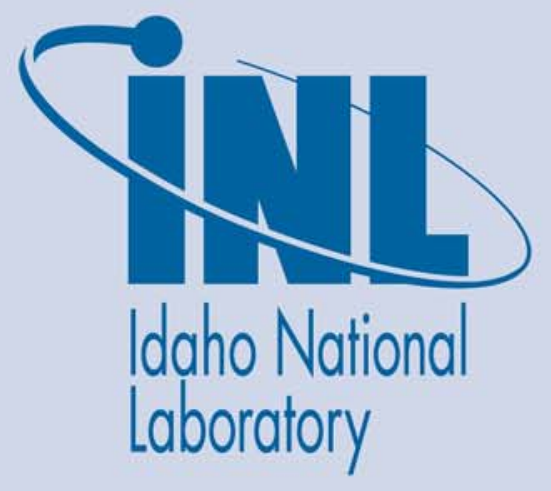

The INL is a U.S. Department of Energy National Laboratory operated by Battelle Energy Alliance 


\section{DISCLAIMER}

This information was prepared as an account of work sponsored by an agency of the U.S. Government. Neither the U.S. Government nor any agency thereof, nor any of their employees, makes any warranty, expressed or implied, or assumes any legal liability or responsibility for the accuracy, completeness, or usefulness, of any information, apparatus, product, or process disclosed, or represents that its use would not infringe privately owned rights. References herein to any specific commercial product, process, or service by trade name, trade mark, manufacturer, or otherwise, does not necessarily constitute or imply its endorsement, recommendation, or favoring by the U.S. Government or any agency thereof. The views and opinions of authors expressed herein do not necessarily state or reflect those of the U.S. Government or any agency thereof. 


\title{
Nuclear Innovation Workshops
}

September 2015

\section{Idaho National Laboratory Idaho Falls, Idaho 83415}

\section{http://www.inl.gov}

\author{
Prepared for the \\ U.S. Department of Energy \\ Office of Nuclear Energy \\ Under DOE Idaho Operations Office \\ Contract DE-AC07-05ID14517
}





\begin{abstract}
Innovation is commonly defined as a new idea, device, or method. It can fulfill an essential role in developing and implementing the strategies and capabilities for improved production and utilization of energy resources. The Nuclear Innovation Workshops held March 3-5, 2015, provided intriguing insights into innovations that are judged by a diverse sampling of today's nuclear-energy enterprise to be most important and hold the greatest promise. As might be expected, the most frequently discussed innovations are directed toward policy, investment, human capital, and communication of the importance of nuclear energy for achieving an economic and environmentally responsible energy future. The most frequently discussed technologically innovative ideas aim to enable commercialization of concepts that are already conceived and in various stages of development.

Interestingly, a background theme of the workshops was that a lack of innovative ideas was not necessarily perceived as a primary issue. Instead, an inability to implement innovative ideas in the face of multiple institutional, rather than technical, obstacles took center stage. These institutional obstacles included (1) inconsistent and incomplete research-and-development program progression; (2) continuously varying priorities due to uncertain government energy policies; (3) barriers to effective utilization of U.S. Government infrastructure, such as test reactors and material examination capabilities; (4) missing infrastructure that needs to be provided by the U.S. Government, because these capabilities are too expensive for private industry to construct; and (5) inadequate U.S. Government participation in commercialization of innovative nuclear energy technologies.

This document summarily captures the overall workshop discussion themes and is written for use by the U.S. Department of Energy, with suggestions for future actions.
\end{abstract}




\section{CONTENTS}

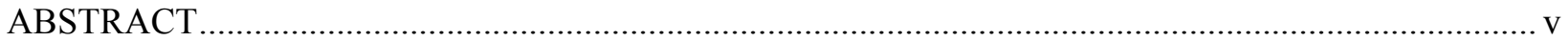

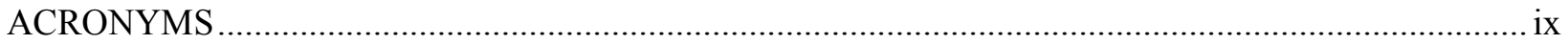

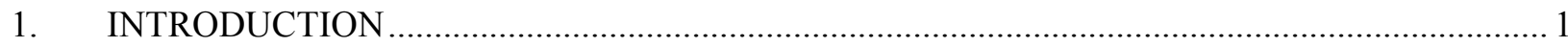

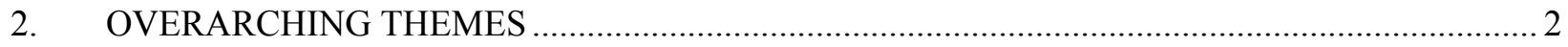

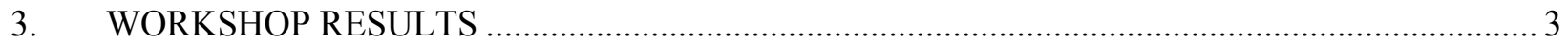

3.1 Designate National Test Beds or Platforms that Provide Access to Essential

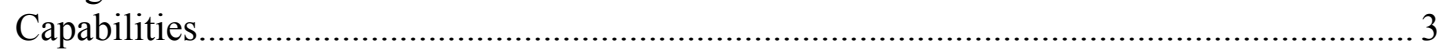

3.2 Improve Approaches for Incorporating Advanced Nuclear Energy Technologies in Regulatory Requirements.............................................................................................. 5

3.2.1 Potential for New or Revised Regulatory Technical and Policy

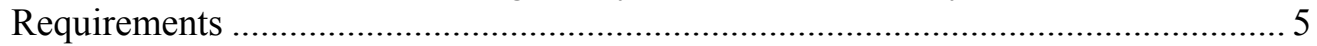

3.2.2 Regulatory Authority at DOE-Owned Facilities...................................................... 5

3.2.3 Reinforce Engagement among Federal Agencies, the Research Community, and The Parts of Industry That Have an Interest in Developing Innovative

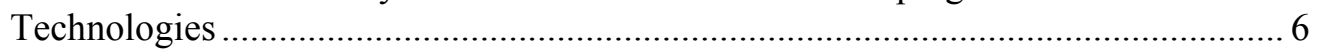

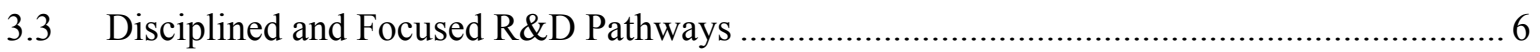

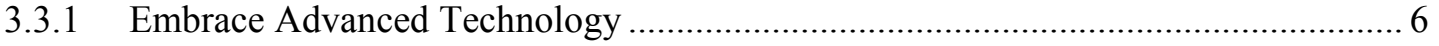

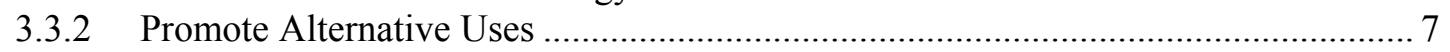

3.3.3 Learn from Other Industries.................................................................... 7

3.4 Opportunities for Technical Innovation ........................................................................ 7

3.4.1 Advanced Reactor Concepts and Fuel Technologies.......................................... 7

3.4.2 System Diagnostics, Feedback, Control, and Facilitated Inspections ........................ 8

3.4.3 Implementation of Improved Materials, Manufacturing, and Construction

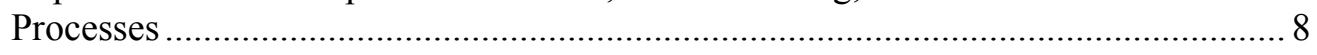

3.4.4 Deployment and Siting Considerations.......................................................... 9

3.5 Develop Better Communications to Reinforce the Value of Widespread Use of

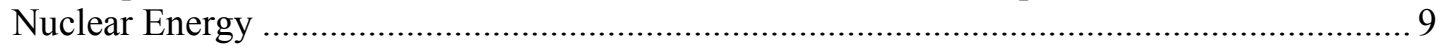

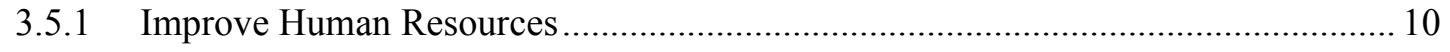

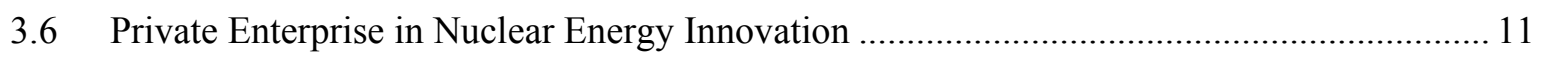

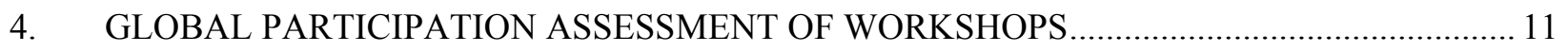

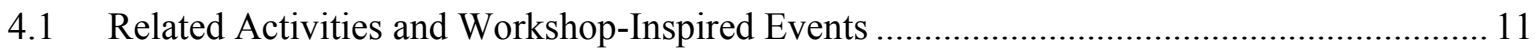

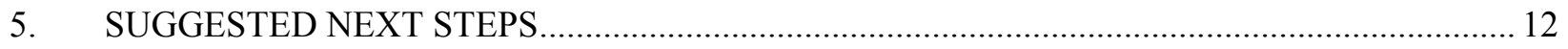

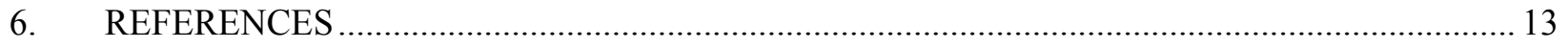

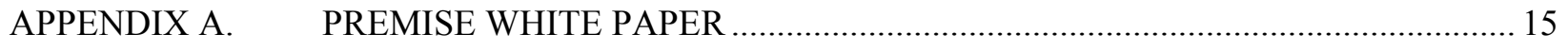

APPENDIX B. WORKSHOP LEADERSHIP AND ORGANIZATION ...................................... 17

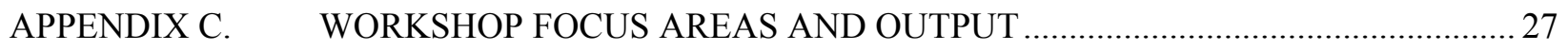

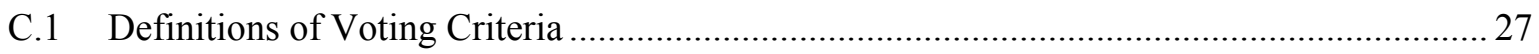


C.2 Summarized Output From Main Workshops …........................................................ 28

C.2.1 Focus Area 1: Use of Innovative Concepts...................................................... 28

C.2.2 Focus Area 2: Innovative Use of Existing Technologies ..........................................29

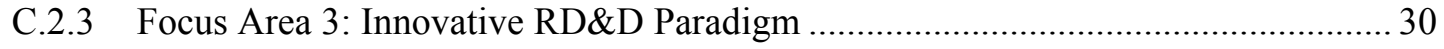

C.2.4 Focus Area 4: Innovative Licensing Paradigm ....................................................... 32

C.3 Summarized Output from Advanced Manufacturing \& Supply Chain Conference

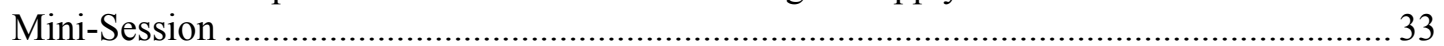

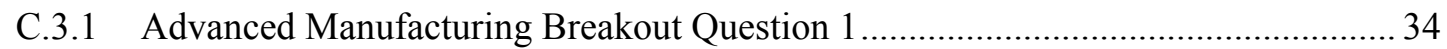

C.3.2 Advanced Manufacturing Breakout Question 2 2..................................................... 34

C.3.3 Advanced Manufacturing Breakout Question 3 ….................................................... 34

\section{FIGURES}

Figure 3-1. Bridging the "Valleys of Death" with an R\&D test bed and demonstration platform. 4 


\section{ACRONYMS}

$\begin{array}{ll}\text { ANS } & \text { American Nuclear Society } \\ \text { DOE } & \text { U.S. Department of Energy } \\ \text { HGTR } & \text { high-temperature gas-cooled reactor } \\ \text { INL } & \text { Idaho National Laboratory } \\ \text { NGNP } & \text { Next Generation Nuclear Plant } \\ \text { NRC } & \text { U.S. Nuclear Regulatory Commission } \\ \text { R\&D } & \text { research and development }\end{array}$




\section{Nuclear Innovation Workshops}

\section{INTRODUCTION}

An important part of the U.S. Department of Energy (DOE) mission is to encourage innovation in energy production and facilitate its implementation to ensure the efficacy of U.S. energy production. Nuclear energy represents a key component in our nation's technology portfolio to help achieve the goal of providing a clean, secure energy source. Growth of the nuclear industry has been relatively stagnant for several decades, as has America's historically strong leadership in nuclear energy. As a result, a set of six simultaneous Nuclear Innovation Workshops was organized by Idaho National Laboratory (INL) to crowdsource forward-looking ideas regarding the use of nuclear energy technologies to help tackle energy challenges facing our nation and the world. These workshops were held March 3-5, 2015, at Oregon State University, Boise State University, University of New Mexico, The Ohio State University, Massachusetts Institute of Technology, and North Carolina State University.

The six workshops brought together views and ideas from a diverse cross section of 125 thought leaders selected from universities, national laboratories, federal agencies, industry, and public policy organizations, including a small number of participants from Europe. Participants were selected by the workshop organization team, which included INL leaders, six university hosts, and six national laboratory technical leads. Each workshop was limited to fewer than 25 participants in order to provide an atmosphere conducive to the emergence of regional themes.

The workshops were conducted in structured format using collaborative ThinkTank software (ThinkTank, 2015), so that the top ideas could be ranked nationwide immediately following the conclusion of brainstorming sessions. Prior to the workshops, participants received a white paper (Appendix A) describing the philosophy and established goals for the workshop. During the workshop, four primary focus areas were explored to generate innovative technology ideas supporting the long-term objective of replacing and expanding current nuclear capacity in the U.S., with emphasis on:

- Affordable electricity generation cost with emphasis on capital cost reduction

- Better integration with a dynamic grid that includes growing renewable energy input

- Enhanced safety and security

- Reduced environmental impact

- Reduced proliferation risk

- Improved resource and waste management.

The four focus areas included innovative concepts; innovative use of existing technologies; an innovative research, development, and demonstration paradigm; and a licensing paradigm that facilitates innovation. Within these focus areas, several questions were posed for consideration by workshop participants using techniques to facilitate brainstorming. Then multiple one-on-one discussions were followed by a bartering-based scoring system to establish the top three ideas for each workshop site. In turn, group discussions refined topics into consensus ideas, followed by rating and ranking of the likelihood that the innovation idea would positively affect the points of emphasis listed above. 
Prior to the workshop, participants were urged to focus, to the extent possible, only on technical issues associated with innovation leading to rapid commercialization. Time constraints prohibited a discussion of innovation in equity investment and debt financing of research, development, demonstration, and deployment, which are understood to be important parts of the energy solution. Innovation in advanced manufacturing was captured in a follow-on breakout session at the Advanced Manufacturing \& Supply Chain Conference held in Pocatello, Idaho, on May 18-20, 2015. While process and policy were generally set aside to allow technical issues to take center stage per original guidance, process and policy naturally became part of the conversations.

It is important to place output from the workshops in the appropriate context. Organizers (Appendix B) intentionally chose a diverse cross section of participants in order to capture perspectives from those who may not be involved in the nuclear energy industry on a regular basis. The resulting data reflect this diversity and are therefore not always what would be expected from those well versed in nuclear energy systems and energy policy. Further, the predominance of university and national laboratory participants compared with industry representatives created an imbalance with unintentional consequences. Namely, industry input on process and policy issues that strongly affect the marketplace and business decisions was discussed at some length among industry participants during the meetings but was not emphasized in the workshop summaries. It is also evident that the technical community outside of industry generally does not have a comprehensive understanding of how regulatory requirements are established and how the U.S. Nuclear Regulatory Commission (NRC) licenses and regulates nuclear energy technologies. These topics are considered possible opportunities for future focused innovation workshops.

\section{OVERARCHING THEMES}

Overarching the themes were private conversations suggesting that the U.S. Government should further encourage the private sector to invest in the development and commercialization of innovative nuclear energy technologies and advanced nuclear energy systems. A number of private interests of varying sizes are already investing in the early development of advanced nuclear energy systems. This can be further encouraged through broader use of grants and cooperative agreements per 2 CFR 200 (2 CFR 200 "Uniform Administrative Requirements, Cost Principles, and Audit Requirements For Federal Awards", 2015) that can expand development and eventual commercialization of promising innovative and advanced concepts. Grants can be focused on early startups and cooperative agreements for cost-shared, public-private partnerships to help defray the considerable costs associated with commercialization of nuclear energy technologies.

Rather than discussions based solely on ideas themselves, unanticipated discussions emerged on ways to remove obstacles hindering implementation of innovative technical ideas. Although specific technical ideas were discussed, general supporting commentary for the most part tended to steer toward:

- The inconsistent and incomplete progress of research-and-development (R\&D) programs

- Continuously varying priorities due to uncertain government energy policies

- Barriers to effective utilization of U.S. Government infrastructure, such as test reactors and material examination capabilities

- Missing infrastructure that needs to be provided by the U.S. Government, because these capabilities are too expensive for private industry to construct

- Inadequate U.S. Government participation in commercialization of innovative nuclear energy technologies. 
It is entirely natural to be focused on addressing issues that prevent the "real work" from occurring in order to remove distractions and allow concentration on solving complex technical issues. In other words, in order for true innovation to occur, certainty in policy and processes must exist.

It is evident based on the workshop discussions that the U.S. does not lack technical innovation. Numerous innovative technical ideas exist, but an environment must be created that facilitates innovation in order for these ideas to be developed and commercialized. Considering the large investment required for development and commercialization, the U.S. Government must play an important facilitating role to ensure innovation occurs.

\section{WORKSHOP RESULTS}

An exercise conducted at the conclusion of the workshops involved site-by-site summarization that was shared live with all sites. A national laboratory technical lead from each workshop site collected local leading topics of conversation, as well as consistent themes that emerged during brainstorming sessions. Although regional focus was encouraged through careful selection of participants, as well as guidance from organizers, regional themes did not generally emerge.

The results summarized below represent those that emerged during this final exercise, during selected discussions within the individual workshops, and through a post-workshop summarization of the collaborative ThinkTank software's output data. Responses to the questions posed by organizers during the workshops are extensive and not included in entirety in this report. Organizers have used the ThinkTank software interface to categorize and summarize the output data. This summary is included in Appendix C of this report. Raw data in full are available (Idaho National Laboratory, 2015) on the workshop website (https://nuclearinnovationworkshop.inl.gov/SitePages/Home.aspx) or by request to the INL Communications Department (http://www.inl.gov). The top themes that emerged from these workshops and follow-on discussions are provided below.

\subsection{Designate National Test Beds or Platforms that Provide Access to Essential Capabilities}

Better utilization and possible expansion of current R\&D capabilities are needed to provide more extensive support for fundamental technology development that can improve nuclear energy. Additionally, characterization and appropriate improvement of the infrastructure, and investment in intellectual resources at national laboratories, are needed to help support both development and commercialization. One of the most commonly cited reasons for a lack of innovation in nuclear energy is the difficulty associated with access to facilities and infrastructure necessary for highly specialized and often hazardous studies that are fundamental to ensure safety and reliability in nuclear reactors. The testbed concept could encompass a range of features - from fundamental research platforms for conducting separate effects testing and reducing developmental technology risks all the way to a full-scale reactor prototype to support commercialization. The concept and scope of such test beds require considerably more discussion, and the topic is a candidate for a near-term focused workshop. Development of such infrastructure, along with facilitated access and regulatory oversight commensurate with demonstration activities, are suggested as requirements to advance nuclear energy in the U.S. and the world. Existing regulatory guidelines (NUREG-1537, 1996) complement commercial power reactor licensing and could enable an appropriately regulated national test bed or demonstration platform.

The test bed and demonstration platform address two different phases of movement from concept to reality. The first phase, which is covered by the test bed and sometimes referred to as the "First Valley of Death," rapidly and cost-effectively retires technical risk for innovative technologies. The second phase, which is covered by the demonstration platform and sometimes referred to as the "Second Valley of Death," reduces commercialization costs and associated risks for deploying initial commercial units. 
Figure 3-1 depicts the location of the R\&D test bed and demonstration platform with respect to maturation of technology.

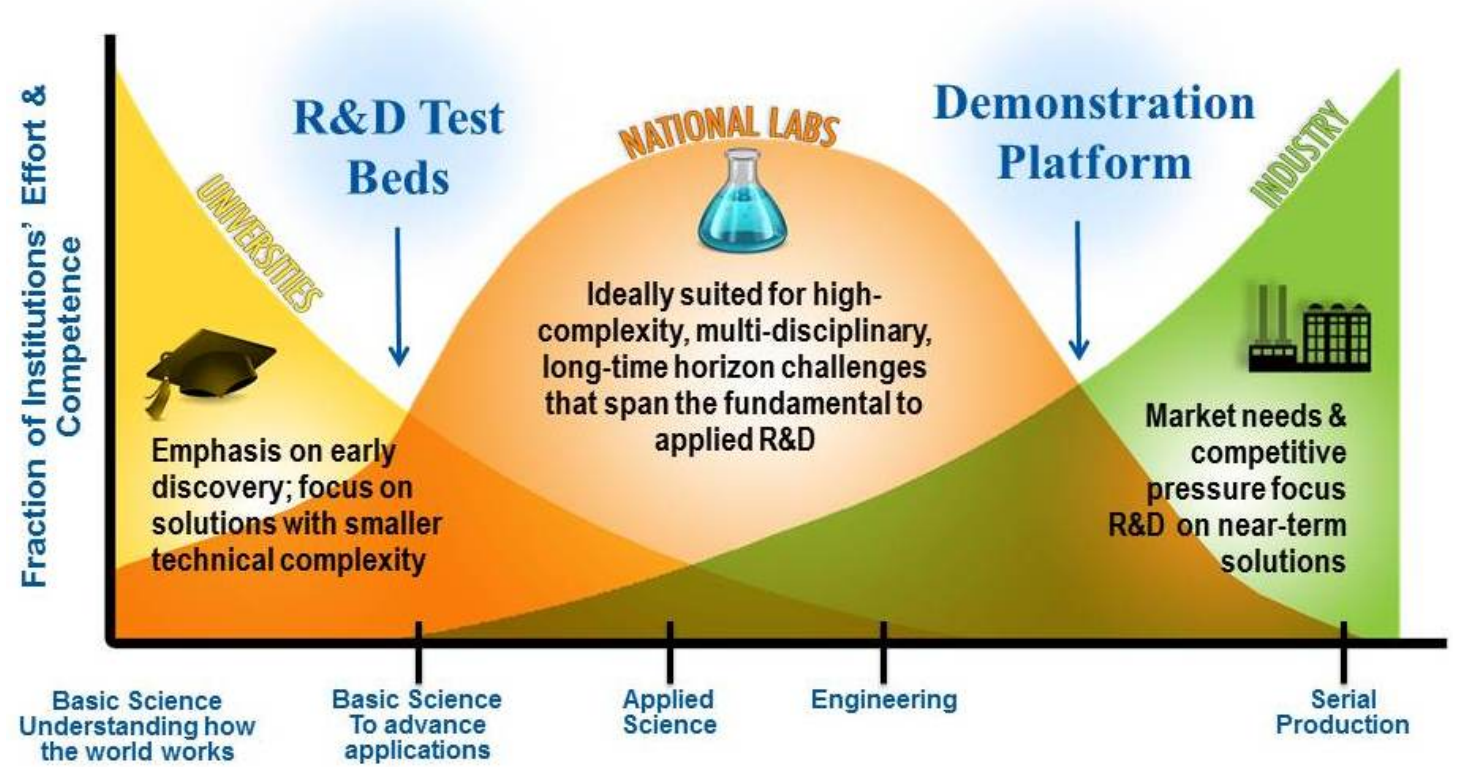

Figure 3-1. Bridging the "Valleys of Death" with an R\&D test bed and demonstration platform.

Access to very specialized and expensive equipment is a benefit afforded by a conceptualized test bed. Existing examples in the nuclear energy world include DOE's Nuclear Science User Facilities, which offer access to test reactors, hot cells, and post-irradiation examination equipment, as well as intellectual capital at national laboratories and universities. This infrastructure consists of the specialized and expensive equipment that private industry either would not, or could not, invest in. It is essential that industry, academia, and innovative entities have access to these national assets through collaborative agreements or partnerships.

The workshops generated several suggestions for technology development capabilities that would need to be included in a test bed or user facility. These capabilities include a new fast test reactor that would enable development of fast-reactor technologies and accelerated development of radiation-resistant materials. The fast reactor would complement existing test reactors, such as the Advanced Test Reactor at INL and the High Flux Isotope Reactor at Oak Ridge National Laboratory.

A future demonstration platform would reduce costs to commercialization by having access to sites that are secure, are well characterized, and have pre-existing connections to the power grid and requisite utilities. A DOE national laboratory could serve in this role. Full-scale demonstrations of reactor concepts would be enabled by a demonstration platform that is provided by the private sector and utilizes a national laboratory site.

The capabilities at government sites, particularly DOE national laboratories, provide the opportunity to establish a well-configured route to developing the regulatory requirements needed for subsequent licensing of advanced commercial nuclear energy systems. This development can include research- and test-reactor capabilities for foundational (theoretical-level) experimentation and extension of such results into practical demonstrations supporting commercial licensing. Licensing pathway options for such experimentation and demonstration include both DOE self-regulation and NRC regulation, depending on the specific nature and purposes of the facilities. The specific mechanisms for developing regulatory 
requirements (most of which already exist) could be adjusted and matured for advanced reactor technologies to reduce the overall regulatory risk and investment uncertainty. These risks and uncertainties are important hurdles that must be overcome by either private industry or government.

\subsection{Improve Approaches for Incorporating Advanced Nuclear Energy Technologies in Regulatory Requirements}

During workshop discussions, it became apparent that non-industry participants had a limited understanding of the processes used by NRC to establish regulatory review requirements and to license nuclear energy technologies. Consequently, a separate focused workshop on these subjects is warranted. The following provides a high-level summary of some areas discussed during the workshop.

\subsubsection{Potential for New or Revised Regulatory Technical and Policy Requirements}

As established by Congress, today's regulatory priorities focus on existing nuclear energy facilities, which are based on use of light water reactor technologies. However, discussions with NRC on innovative and advanced nuclear concepts are under way. Based on workshop and outside discussions, a common misperception appears to be that the U.S. regulatory process inhibits innovation. In fact, establishment of priorities and NRC funding for advanced technology work are the primary issues. Consequently, workshop participants suggested that congressional realignment of NRC's priorities and a cooperative approach by NRC and DOE are warranted to encourage innovative and advanced nuclear energy concepts. This approach could utilize a number of existing resources. The NRC's Office of Nuclear Reactor Regulation research and test reactor licensing processes could inform R\&D activities for innovative and advanced nuclear energy technologies. Additionally, NRC's Office of New Reactors could offer processes for commercialization and construction of facilities utilizing such concepts. Continuing cooperative activities are warranted from both DOE and NRC to establish the fundamental regulatory requirements for such technologies and the utilization of reactor test-bed concepts.

The current regulatory framework can be used to make the needed changes to technical and policy requirements for licensing of advanced nuclear energy technologies. Rather than attempting to initially change regulations, white papers on selected topics, topical reports, and use of exceptions and exemptions to current regulation can be used until advanced energy technologies have been vetted and a first-of-a-kind reactor has been licensed via this alternative pathway. This alternative pathway has been used by the Next Generation Nuclear Plant (NGNP) Program for high-temperature gas-cooled reactor (HTGR) technology in several key areas (e.g., license basis events, mechanistic source term, functional containment concepts, and emergency planning) consistent with the joint NRC/DOE report to Congress in August 2008 (DOE-NRC, 2008). What remains for the NGNP Program in these areas is for the NRC to make policy decisions required by the scope of necessary changes to technical requirements. The safety basis for HTGR technology can then be realized.

The concept of modified NRC funding arose several times during the workshops. NRC is funded primarily by current licensees and by design-certification and site-license applicants. NRC is allowed some flexibility in addressing non-light water reactor technologies and has exercised this flexibility in the past on a case-by-case basis. In order for NRC to have the ability to significantly focus resources on innovative and advanced technologies, however, Congress would need to support changes to NRC priorities and provide the additional directed funding. This is a suggested part of the so-called "NRC reform" advocated by some workshop participants.

\subsubsection{Regulatory Authority at DOE-Owned Facilities}

NRC has the authority to license research, test, and commercial reactors, including prototypes. DOE can only authorize research or test reactors on DOE-owned facilities (e.g., for the purpose of collecting 
data for research, testing of materials, or testing of fuels). DOE can authorize a research or test reactor as long as it is not operated for the purposes of demonstrating the suitability of such a reactor for commercial applications and as long as it is not operated as part of a power-generation facility within an electric utility system.

NRC Chairman Stephen Burns (Burns, 2015) discussed NRC licensing policies as they relate to DOE Nuclear Energy R\&D programs in his recent testimony to the House Committee on Science, Space, and Technology, Subcommittee on Energy. In this testimony, Chairman Burns highlighted several instances of DOE-NRC cooperation whereby NRC reviewed safety cases, issues of licensability, etc. He also pointed out the exceptions to NRC regulatory authority pertaining to testing and demonstration at DOE sites. It appears that consistent communication between all parties involved (federal agencies, industry, and other interested parties) and an understanding of limitations may go a long way toward addressing the ability to innovate in the nuclear arena without completely restructuring current regulations.

\subsubsection{Reinforce Engagement among Federal Agencies, the Research Community, and The Parts of Industry That Have an Interest in Developing Innovative Technologies}

DOE, NRC, and parts of the industry that have an interest in innovation or can identify issues important to maintaining current nuclear fleet should be working closely together. Sharing ownership of research, development, and demonstration improves synergy in several areas, including regulation and enhanced understanding of the approach to setting safety criteria and design requirements, fundamental R\&D necessary to address modern issues (i.e., industry-informed federal R\&D programs), and innovative insight provided by federally supported scientists.

In multiple instances, cooperation between DOE and NRC has resulted from a need to address an advanced technology. Examples cited by NRC Chairman Burns (Burns, 2015) include the Clinch River Breeder Reactor Preliminary Safety Analysis in 1982-83, the pre-application review of the GE-Hitachi PRISM Preliminary Safety Information document in 1987, and the more recent NRC-DOE jointly issued report to Congress on the NGNP Program (DOE-NRC, 2008). The workshop discussions simply pointed to the fact that these cooperative activities need to not only continue but perhaps expand in scope and breadth.

\subsection{Disciplined and Focused R\&D Pathways}

Improved stability of nuclear R\&D funding and programs is vital and should include a specific set of clear, long-term, national priorities that extend for multiple decades. A consistent and long-standing policy on energy is needed; the Quadrennial Energy Review and Quadrennial Technology Review were commissioned for this reason. These likely need time to mature. Although this is generally a policy issue involving Congress, the Office of Management and Budget, and DOE, it surfaced multiple times during the workshops. Some themes branch from this with regard to potential focused R\&D pathways.

\subsubsection{Embrace Advanced Technology}

Multiple examples of existing or near-term technologies (digital instrumentation and control, modular construction, passive safety systems, high-temperature reactors) could be implemented by the nuclear energy enterprise if the economic and safety cases are compelling. For example, several ideas posed during the workshops were ranked according to level of innovation, industry impact, and feasibility of implementation. These ideas were proposed in response to the question, "In the area of nuclear energy systems and subsystems, where are the greatest opportunities for innovation?" The idea ranked most innovative by combined voting of all workshop participants was the direct conversion of nuclear power to electric energy. Direct conversion, analogous perhaps to solar energy, was perceived to be a highly innovative solution for advanced nuclear power stations to primarily address possible increases in 
efficiency. Ideas that were judged by participants to be the best combination of impact and feasibility while maintaining an appropriate level of innovativeness were (1) development and demonstration of advanced reactor design(s) that are truly inherently safe; (2) development of Brayton and other high-efficiency, energy-conversion systems with minimal water consumption, which is important in arid regions; and (3) technologies that accommodate variable production where traditional base-load operation must be modified to address dynamic load and production conditions on the grid.

\subsubsection{Promote Alternative Uses}

Process heat has high potential for use in chemical processes, carbon conversion, etc. Often discussed previously outside this workshop, this was a frequent topic of discussion among participants primarily in response to a question related to positive synergy between the nuclear energy industry and other industries. Other suggestions for continued, expanded use of nuclear energy included production of medical isotopes.

Although not an "alternative" use of nuclear energy, the subject of load following naturally came up in workshop discussions. The subject included discussions involving large-scale energy storage, such as battery concepts that would presumably aid in load-following ability but also to potentially allow controlled release of energy to meet variable demands and improve the economics of energy distribution.

\subsubsection{Learn from Other Industries}

Summaries of discussions from the various workshop sites suggest that studying examples of successes in other industries would be beneficial to the nuclear energy industry. Areas that could be studied include socialization, regulatory models (aviation, pharmaceutical, etc.), and construction techniques. The nuclear energy community could benefit from proactively adopting lessons learned from other industries. Foremost among lessons suggested for adoption were those related to regulatory oversight. This theme appears in response to questions regarding synergy between nuclear energy and other industries, as well as in response to a question involving improvement of the regulatory paradigm.

An "XPRIZE" (XPRIZE Foundation, 2015) type approach was suggested multiple times during the workshop. This approach has resulted in varying degrees of success in promoting rapid development of cost-effective and advanced space flight. The Ansari XPRIZE, which was the motivation for this type of approach, was a cash award provided by a group of entrepreneurs to the winner of a competition to be the first non-government organization to launch a reusable, manned spacecraft into space twice within 2 weeks. Potential for innovation in advanced nuclear energy systems is perceived to be enhanced by a more openly competitive "blue sky" approach.

\subsection{Opportunities for Technical Innovation}

Most of the questions posed to Nuclear Energy Innovation Workshop participants were intended to capture purely technical innovations, including purely new innovations, innovative improvements to existing technology, innovative adaptation of technologies existing in other industries, and idealistic reformulation of nuclear energy systems as a whole. While discussions tended toward larger obstacles to innovation, several innovations were posed in response and decided upon by group consensus as beneficial to the nuclear energy industry. Note that for several of the brainstorming sessions during these workshops, participants were asked to set aside inhibitions caused by the perceived feasibility of an idea; this was done to explore as many ideas as possible and potentially figure out how to make them feasible later on.

\subsubsection{Advanced Reactor Concepts and Fuel Technologies}

High-temperature reactors for efficiency improvement, a closed fuel cycle, inherent or intrinsic safety, and alternative energy transfer media were discussed often at the various workshop sites. Suggestions for improving efficiency included use of concepts such as a Brayton cycle gas turbine 
connected to HTGRs, direct conversion of fission energy to electricity, alternative heat transport media, and forms of load following, including use of battery systems or the ability to switch energy outputs (heat/electricity). Fast-spectrum reactors were suggested for higher temperatures and greater efficiency. Scalability and modularity of reactors, as well as hybrid systems, were posed as a means of improving the economy of construction and operation.

Fuel technology discussions tended to focus on enhanced safety and improved economics, including accident-tolerant fuels, a closed fuel cycle, and waste repositories. Waste minimization was clearly a topic of interest to participants (closed cycle with reprocessing, alternative fundamental reactor designs, etc.). The need to develop accident-tolerant fuels and fuels that improve efficiency were recognized as areas of continued interest for innovative $R \& D$.

\subsubsection{System Diagnostics, Feedback, Control, and Facilitated Inspections}

Modernization of feedback and control-systems is well recognized as a need within the complex of existing nuclear energy facilities. Workshop suggestions for innovative advancement centered on using all digital control systems in plants, improved health monitoring, and advanced inspection tools, including improved human-machine interfaces. It was pointed out that with some of these advanced systems comes additional cyber security risk. An example of an innovative solution to improvement of instrumentation and control is a completely wireless system that would facilitate operations, particularly in the event of an accident. With the inclusion of a technology such as this, however, extra diligence would be required for security.

Proposed solutions for improved inspection and plant-health monitoring solutions included expanded use of advanced robotics. Other proposed solutions included remote inspection and visualization aids, such as a Google Glass-equivalent system, that would enable operators to potentially overlay critical information with what they see in front of them, thus speeding up and enhancing inspections and monitoring.

\subsubsection{Implementation of Improved Materials, Manufacturing, and Construction Processes}

A significant portion of the discussion on technical innovation involved suggestions for improving materials and processes used in the construction and repair of nuclear systems. This was also a prevalent topic during a breakout session of the Advanced Manufacturing \& Supply Chain Conference held shortly after the innovation workshops.

Advanced, radiation-resistant materials remain at the forefront of innovative technological improvements, because these materials could be tailored for higher temperatures and extended lifetimes in nuclear reactor internals. Along with suggestions for development of these materials were suggestions for increased use of advanced manufacturing methods, such as additive manufacturing that could aid in advanced, radiation-resistant materials production. These materials include both internal structural materials and fuel cladding, where the ability to withstand extreme temperatures and radiation while still allowing efficient transfer of heat is highly beneficial. Workshop commentary noted that part of improvement in cladding materials would naturally be coupled with advanced fuel concepts, because the synergy between fuel and cladding is critical to energy production.

Combined with advanced materials production are advanced materials-processing techniques. Innovative use of advanced material-joining techniques, such as friction stir welding, electron-beam welding, and inertia welding, could help to more efficiently repair and construct advanced materials. Material processing, including such technologies as water jet peening or laser peening, could help condition materials to be less susceptible to environmental failure. 
Modular construction of nuclear facilities was suggested as a way to improve the economics of construction and repair. This would include large modular parts that are standardized for specific reactor types. Workshop commentary pointed out that modular construction would require high parts volume, which may necessitate international standardization.

Finally, more integrated use of computational tools could increase efficiency in design and construction. Increased automation and computer control could also potentially remove variability from labor-intensive processes.

\subsubsection{Deployment and Siting Considerations}

As a means to improve distribution efficiency and potentially improve development and construction efficiency for new nuclear plants, suggestions were made in the workshop concerning intricacies of plant deployment and siting.

With regard to deployment, distributed energy was a topic of some interest. This concept arose multiple times in the form of micro-reactors or small reactors that could be relatively easily sited and deployed. These concepts were extended to the ability to deploy power in remote locations that have no ready access to supporting infrastructure.

Siting of nuclear power plants was discussed in the context of taking advantage of need, geographical characteristics, and community consent. A suggestion that takes advantage of potential need, as well as geographical characteristics, was offshore (floating) power plants. These could presumably be moved to multiple locations and could take advantage of a large heat sink for decay heat removal. Siting of power stations based on need as well as community consent to facilitate placement was another topic that was discussed in the workshops.

\subsection{Develop Better Communications to Reinforce the Value of Widespread Use of Nuclear Energy}

There is growing international recognition of nuclear energy's value in providing economically stable and environmentally clean energy. Communicating this value in a simple, evidence-based way is necessary. Successful outreach must credibly emphasize the importance of nuclear energy for a prosperous and environmentally responsible future. Prevalent in workshop discussions was the suggestion that efforts should be made to educate the public via outreach programs (e.g., frequent television spots analogous to those from the American Petroleum Institute, America's Natural Gas, and the American Coalition for Clean Coal; stronger emphasis on nuclear energy as a clean energy source in K-12 education programs; educational seminars for local and regional consumption). Another outreach example cited at The Ohio State University workshop was the development of a seminar series or workshops in the academic and national laboratory environment that address questions such as:

- How was nuclear energy technology derived, and intentionally separated, from nuclear weapons development?

- Why is the light water reactor technology the current dominant choice in the U.S. and worldwide for nuclear power?

- What are the important drivers that will influence industry use of advanced nuclear energy technologies?

In addition to targeted in-person seminars and workshops, addressing these and other public concerns requires simultaneously using conventional and emerging communication methods. The path forward for innovation in communication methodology was not discussed at length during the workshops, but subsequent discussions among some workshop participants has initiated interest in potential follow-on focus and activity. 
While the "information deficit model" is still highly valuable in communicating about nuclear technologies, the Internet age has marked the emergence of the "engagement model of science communication" (Groffman, et al., 2010). The information-deficit model is based on education models, which include a clear hierarchical dynamic between a teacher and a student or an expert and a layperson and facilitate direct knowledge transfer. The engagement model is a flattened, multi-directional approach that has emerged as digital communication has become more common. These models are complementary tools for communication about nuclear technologies and can be applied by themselves or in combination, depending on the platform and audience.

With regard to specific messaging, recent analysis suggests that the inclusion of values-based messages may help to increase public support for nuclear technologies. Researchers at Cardiff University in Wales (Demski, Butler, Parkhill, Spence, \& Pidgeon, 2015) conducted an extensive qualitative study and have defined underlying values that guide preferences and perceptions of various energy technologies.

These values include:

- Efficiency and not wasting - being more efficient (doing more with less) and minimizing waste and overall energy usage (these characteristics are nearly universally seen as being positive)

- Protection of the environment and nature - being environmentally conscious and respectful of nature

- Ensuring security through reliability, affordability, availability, and safety - making sure the energy system is safe, reliable, and accessible to citizens both in terms of affordability and availability

- Autonomy and power - being mindful of the importance of autonomy and freedom at national and personal levels

- Social justice and fairness - developing energy systems in ways that are open, transparent, fair, and attentive to the effects on people's abilities to lead healthy lives

- Improvement and quality - thinking in terms of long-term trajectories, ensuring changes represent improvement.

In the era of digital and social media, communication methods are evolving rapidly, necessitating regular assessment and updates. Although communication methods were not explicitly discussed during the workshops, there was agreement that communications efforts throughout the nuclear sector will benefit from continued values-based message alignment and increased resources to maximize reach and impact.

\subsubsection{Improve Human Resources}

Less directly related, but related nonetheless, to communication improvements are improvements in human resources within the nuclear industry. Workshop comments touched on topics such as addressing knowledge transfer vulnerabilities and focused education programs. General methods for improving education and leadership within the nuclear energy community were also put forth.

The DOE, NRC, and National Nuclear Security Administration currently participate in the Integrated University Program, which is designed to promote work-force development. The DOE, through its Nuclear Energy University Program, offers competitive scholarships and fellowships to students who are committed to entering an accredited nuclear science, engineering, or related field of study at a college or university (NEUP Student Educational Support, 2015) approved by the Integrated University Program. The NRC and National Nuclear Security Administration offer similar programs. 


\subsection{Private Enterprise in Nuclear Energy Innovation}

As expected in a forum dedicated to innovation, discussions involving the ability of entrepreneurs and private enterprise to contribute to the advancement of nuclear energy technology were implicit in these workshops. It is recognized that multiple non-federal entities are focused on new reactor concepts, fuelcycle improvement, waste management, and energy transfer. Indeed, a recent article appearing on the Third Way website (thirdway.org) lists 49 entities who are pursuing what is termed "advanced nuclear" (Brinton, 2015). The list provided in the article includes technologies that vary considerably in maturity, complexity, and nature. The author notes that these private entities are not isolated to specific regions, technologies, or sizes. From an innovative standpoint, it is of interest to see that more than 10 of these small to large private companies are investing in fusion-based, rather than fission-based, nuclear power. Additionally, there are obviously innovations in alternative coolants and energy transfer media, with only a handful examining alternative fuel technologies.

Clearly, numerous entities are involved in what is considered innovative nuclear power. The interest in these technologies by companies that sell nuclear-energy systems and produce energy (industry) is far less clear. Several of these technologies are likely to be monitored in the background by industry but may not elicit enormous support until they are proven to address a safety mandate or improve economics (e.g., reduce construction costs, consume considerably less fuel, etc.). It should be noted that innovative R\&D is only part of the solution for bringing innovation to market. Commercialization that would be carried by large entities such as DOE or industry represents the other part of the solution. Only a few of the 49 entities listed in the Third Way article are focused on commercialization in addition to R\&D. Industry is primarily driven by improved safety characteristics and options for alternative markets. This is precisely why more, and better, facilitated public-private partnerships are imperative for innovation in nuclear energy.

An article in the May/June 2015 ANS News (Piercy, 2015) suggests a move to an incubation model in support of development of advanced reactor concepts as opposed to the historically relied upon gestation model. The incubation model requires federally supported technical user facilities that are accessible to private industry, a modified regulatory approach that is flexible enough to allow accelerated innovation, and a demonstration platform for proving concepts. As discussed in the ANS article, under this model, private enterprise drives technological processes through its own investments rather than in response to a technology that is down selected through a federal process. This presumably enhances our ability to innovate in a more expedient fashion.

\section{GLOBAL PARTICIPATION ASSESSMENT OF WORKSHOPS}

Traditional and social media outlets were used to communicate information about the workshops while in progress. These activities generated approximately 4 million interactions on Twitter, and an Associated Press article about the events ran in at least 150 news outlets in 31 states and six countries. Publications that ran the article included The New York Times and The Washington Post. Additionally, ABC News aired a segment on the workshops. A number of in-depth and ongoing conversations were established both online and offline as a result of media coverage and social interactions. The level of public dialogue surrounding the workshops is a positive indicator that the recommendations resulting from the event are timely and socially supported nationally and internationally.

\subsection{Related Activities and Workshop-Inspired Events}

Since the completion of these workshops in March 2015, and especially following the Executive Summary release in June 2015, several events have been held and actions taken that are of interest to the organizers and those following the evolution of this movement. These Nuclear Energy Innovation Workshops were simply a starting point. Follow-on discussion and inspiration are among the goals of conducting workshops such as these. 
Within days of the workshops, for example, one participant posted two articles to the Nuclear Diner blog reflecting on what worked and what did not work well with regard to the workshops (Rofer, \#NukeInnovation: What We Discussed, 2015), (Rofer, \#NukeInnovation: What We Didn't Discuss, 2015). The author highlighted three central themes that emerged in terms of aiding innovation in nuclear energy: consistent funding, creation of a test facility, and more relevant regulation. The author also stressed the need for innovation in improving societal awareness of nuclear energy, which the author suggested was not discussed in the workshops. (Workshop data suggest this issue was discussed, albeit less than other issues.) The second blog post posed interesting discussions on national laboratory funding issues and industry regulatory issues.

The above-referenced Third Way article, "The Advanced Nuclear Industry," included a discussion of private enterprise in advancement of nuclear energy (Brinton, 2015). The article highlights the surprisingly large number of private entities pursuing innovative ideas in nuclear energy, ranging from fusion reactors to small modular reactors.

And in June 2015, participants at a focused workshop at the nonprofit Center for Advanced Engineering Research discussed the potential use of the resident Integrated Systems Test facility to fill national infrastructure gaps (Summary from the Innovation Workshop for Integrated System and I\&C Testing, 2015). Efforts such as this begin to potentially address the discussed need for a national test bed and a development and demonstration platform.

Collaborations between guest authors and the workshop organizers generated an Energy Collective blog series that has been steadily providing insight into the themes that emerged from the workshop (Allen, 2015). This series parallels the themes of this report but adds additional perspective offered by the guest co-authors.

\section{SUGGESTED NEXT STEPS}

A comprehensive study of the data resulting from the Nuclear Energy Innovation Workshops and collected via ThinkTank software provides insight into where we go from here. While enabling innovation in nuclear energy is a multi-faceted challenge, it is encouraging that so many are focused and interested enough to participate in discussions such as this and offer insight into how to enhance the evolution of nuclear energy. Based on the results of this set of workshops, the suggested next steps include the following:

- Hold a workshop focused on obstacles to technical innovation, and formulate a strategy for removing these obstacles.

- Plan workshops on several of the emergent innovation themes resulting from this workshop. Examples include development of a national test bed, human resources in nuclear, government encouragement of private investment, improved regulatory development for innovative, and advanced technologies.

- Develop approaches to better utilize existing national test-bed and a national demonstration platform capabilities to address two so-called "Valleys of Death" that must be crossed to develop new nuclear energy technology. Identify additional capabilities required to fulfill these capabilities.

- Diversify input. It is recognized that learning from other industries is applicable to innovation in nuclear power. It is also recognized that input from those not generally involved in the nuclear industry, or those who are thought leaders in initiatives such as clean energy, may offer valuable insight.

- Utilize a modernized model of science communication to reach broad audiences via digital media platforms. Of particular importance is alignment with the values of women, young people, and minorities - the key demographics that are currently least supportive of nuclear energy. 


\section{Nuclear Innovation Workshops}

- Conduct feasibility studies, and prioritize technical innovation ideas.

- Incorporate innovative ideas into DOE R\&D roadmaps and formulate requests for information to focus on prioritized technical innovations.

- Continue engaging NRC, and develop a strategy for optimizing NRC regulatory collaboration with DOE to develop and demonstrate innovative technologies.

\section{REFERENCES}

2 CFR 200 "Uniform Administrative Requirements, Cost Principles, and Audit Requirements For Federal Awards". (2015, September). Code of Federal Regulations. Office of the Federal Register.

Allen, T. (2015). A Path for Innovating Nuclear Energy. Retrieved August 2015, from The Energy Collective: http://www.theenergycollective.com/todd-allen/2208896/path-innovating-nuclearenergy

Brinton, S. (2015, June 15). The Advanced Nuclear Industry. Retrieved August 4, 2015, from Third Way: http://www.thirdway.org/report/the-advanced-nuclear-industry

Burns, S. G. (2015, July 29). Written Statement by Stephen G. Burns, Chairman United States Regulatory Commission. Comission to the House Committee on Science, Space, and Technology Subcommittee on Energy.

Demski, C., Butler, C., Parkhill, K., Spence, A., \& Pidgeon, N. (2015, September). Public values for energy system change. Global Environmental Change, 34, 59-69.

DOE-NRC. (2008). Next Generation Nuclear Plant Licensing Strategy. U.S. Nuclear Regulatory Commission.

Groffman, P., Stylinski, C., Nisbet, M., Duarte, C., Jordan, R., Burgin, A., et al. (2010, August). Restarting the conversation: challenges at the interface between ecology and society. Frontiers in Ecology and the Environment, 8(6), 284-291.

Idaho National Laboratory. (2015, August). Nuclear Energy Innovation Workshops Output Data (INL/MIS-15-36465). Science and Technical Information. Idaho National Laboratory.

NEUP Student Educational Support. (2015). Retrieved 2015, from Nuclear Energy University Program: https://neup.inl.gov/SitePages/Fellowship\%20Information.aspx

NUREG-1537. (1996, February). Guidelines for Preparing and Reviewing Applicaitons for Licensing of Non-Power Reactors. U.S. Nuclear Regulatory Commission.

Piercy, C. (2015, May/June). Advanced reactor policy: Moving from gestation to incubation. ANS News, $17(3)$, p. 5.

Rofer, C. (2015, March 10). \#NukeInnovation: What We Didn't Discuss. Retrieved March 13, 2015, from Nuclear Diner ...things nuclear: http://nucleardiner.com/2015/03/10/nukeinnovation-what-wedidnt-discuss/

Rofer, C. (2015, March 9). \#NukeInnovation: What We Discussed. Retrieved March 12, 2015, from Nuclear Diner ...things nuclear: http://nucleardiner.com/2015/03/09/nukeinnovation-what-wediscussed/

Summary from the Innovation Workshop for Integrated System and I\&C Testing. (2015, June 4-5). Retrieved August 15, 2015, from Center for Advanced Engineering and Research: http://www.caer-ist.org/CAER-IST-Workshop-Summary.pdf

ThinkTank. (2015). Retrieved August 2015, from ThinkTank - It's a collaborative process: http://www.thinktank.net

XPRIZE Foundation. (2015). Retrieved August 25, 2015, from Ansari Xprize: http://ansari.xprize.org/ 
Nuclear Innovation Workshops 


\section{APPENDIX A.}

\section{PREMISE WHITE PAPER}

Prior to the workshops, organizers prepared and provided a white paper to workshop participants that was intended to set the stage for the discussions. This original white paper follows here:

\section{WORKSHOP ON INNOVATION IN NUCLEAR ENERGY}

\section{Why We Need Innovation in Nuclear Energy?}

Further innovation is necessary for nuclear energy to provide maximum benefits towards our national goals and to maintain the United States' historical leadership in nuclear energy, which is steadily eroding.

First and foremost, in the short-term, innovative ways of extending the life of the existing fleet while maintaining the stellar safety and security performance, including the management of used nuclear fuel is critical.

For the longer-term, the objective is targeted at replacement and expansion of current nuclear capacity in the United States and increased penetration into the export market by technology innovations aimed at

- Affordable electricity generation cost with emphasis on capital cost reduction

- Better integration with a dynamic grid with large input from renewable energy

- Enhanced safety and security

- Reduced environmental impact

- $\quad$ Reduced proliferation risk

- Improved resource and waste management.

\section{What Kind of Innovation Will Benefit Nuclear Energy?}

It must be recognized that, when we talk about innovation in nuclear energy, we refer to a number of different categories of innovation. They all have an important role to play towards the future vision for nuclear energy, especially when they are all combined in an optimal fashion towards a specific commercialization goal. The DOE-NE roadmap present a comprehensive set of programs at a strategic level that support the vision. Some examples from the existing DOE programs in each category are listed below. Others will be discussed during the workshop. 
The focus of the workshop is on technical issues associated with innovation leading to rapid commercialization. However, policy issues also affect innovation and often drive the need and nature of innovation. The workshop is not focused on the policy issues unless policy considerations directly affect one or more of the technical categories discussed below:

1. Innovative Concepts - This category includes out-of-the box thinking for the design of nuclear energy systems and subsystems in comparison to evolutionary improvements on traditional systems. They can range from a totally revolutionary reactor design to very innovative components adapted to more traditional reactor concepts. In existing programs, Generation 4 (GenIV) reactors (with design that meet the GenIV goals) are reactor examples; accident tolerant fuels are component examples.

2. Innovative Use of Existing Technologies - This category involves using existing or known reactor technologies in a different way than what is being used traditionally. An example would be the nuclear hybrid energy systems. This category also includes technologies that are currently used outside nuclear energy but that can be adapted for use in combination with nuclear energy (e.g. digital control systems).

3. Innovative $R D \& D$ paradigm - For any nuclear energy technology, the traditional and prototype based highly empirical way to conduct RD\&D is lengthy and expensive, which deters the path to commercialization of innovative ideas. An example of the innovative RD\&D paradigm is the "engineering-driven, science-based approach" articulated in the NE RD\&D roadmap.

4. Innovative Licensing Paradigm - The licensing paradigm must parallel the RD\&D paradigm to have the full impact on enabling innovation. For instance, a risk informed decision making process that can translate the results of the engineering-driven science-based approach to a regulatory framework may reduce to cost of and accelerate the licensing process while reducing the overall risk. Risk-informed safety margin characterization (RISMC) methodology is one example that is currently being developed.

\section{What are the Scope and Objectives of the Workshop?}

The workshop participants with the necessary spectrum of expertise will discuss the following during the workshop in a moderated forum with specific questions:

- Future nuclear vision (regional, national and International outlook)

- How are the goals for innovation affected by future nuclear vision - relative importance of the different goals

- Relative importance of innovation categories, additional considerations in each category in terms of strengthening the existing initiatives or adding new initiatives to achieve the desired results in each category.

The workshop outcome is a consolidated report that summarizes the technical discussions with specific recommendations to DOE-NE for enhancements or additions to RD\&D programs in order to enable innovation for the nuclear energy market of the future. 


\section{APPENDIX B.}

\section{WORKSHOP LEADERSHIP AND ORGANIZATION}

The Nuclear Energy Workshops were organized by a team at Idaho National Laboratory (INL) with assistance from hosts and technical leads at each of the six different sites across the United States. University hosts and technical leads were chosen based on their extensive experience and peer recognition in the study of nuclear energy and related subjects. Host sites were the five INL National University Consortium universities (https://www.inl.gov/inl-initiatives/education/nuc/) plus an Idaho University Consortium member (Boise State University). Technical leads were chosen from regional national laboratories to help guide discussions and provide technical assistance in cases where participants may not have had extensive experience with nuclear energy research and development (R\&D). Facilitators were all provided by INL and acted as mediators, discussion leads, and local workshop managers.

The primary organizational team at INL consisted of the following:

Todd Allen - Primary Lead

Kemal Pasamehmatoglu - Technical Lead

John Jackson - Workshop Organizer and Reporting

Phil Hildebrandt - Technical Consultant

K. P. Ananth - Technical Consultant

Suzy Baker - Communications

Nicole Stricker - Communications Consultant

Ray Enge - Workshop Logistics

Linda Elliott - Administrative Support

Lanay Robbins - Administrative Support

The six workshop teams consisted of the following:

Boise State University

Darryl Butt (Boise State University) - Host

Hans Gougar (INL) - Technical Lead

Jody Henley - Facilitator

Oregon State University

Andy Klein (Oregon State University) - Host

Steve Unwin (Pacific Northwest National Laboratory) - Technical Lead

Bryan Parker - Facilitator

\section{University of New Mexico}

Cassiano de Oliveira (University of New Mexico) - Host

D. V. Rao (Los Alamos National Laboratory) - Technical Lead

Mark Gladstone - Facilitator

Ohio State University

Carol Smidts (Ohio State University) - Host

Hussein Khalil (Argonne National Laboratory) - Technical Lead

Lisa Sehlke - Facilitator 
Massachusetts Institute of Technology

Charles Forsberg (Massachusetts Institute of Technology) - Host

Bill Horak (Brookhaven National Laboratory) - Technical lead

Marsha Bala - Facilitator

North Carolina State University

Paul Turinsky (North Carolina State University) - Host

Gary Mays (Oak Ridge National Laboratory) - Technical lead

Allison Conner - Facilitator

\section{Workshop Agenda and Guidance}

The workshop agenda is included here for completeness. The two senior DOE officials referred to here are Dr. Lynn Orr, U.S. Department of Energy (DOE) Undersecretary for Science and Energy (opening), and Dr. John Kotek, DOE Acting Assistant Secretary for the Office of Nuclear Energy (closing). Each of the four focus areas in the workshop were kicked off by a thought-provoking speaker. These speakers, contributing via YouTube videos, were: First Speaker - Kemal Pasamehmatoglu, Associate Laboratory Director for Science and Technology (INL); Second Speaker - Jose Reyes, Chief Technology Officer, NuScale; Third Speaker Jessica Lovering, Senior Energy Analyst, The Breakthrough Institute; Fourth Speaker - Kirsty Gogan, Co-Founder and Director of Energy for Humanity.

\begin{tabular}{|c|c|c|}
\hline & & $\begin{array}{c}\text { DAY } 1 \\
6 \text { Hours 30 Mins. }(10: 30-5: 00 \mathrm{E}) \\
\end{array}$ \\
\hline & 9:30-10:30 & $\begin{array}{l}\text { Final check. } \\
\text { Pre-establish your links with: } \\
\text { - GoToMeeting } \\
\text { - } \quad \text { YouTube } \\
\text { - } \quad \text { ThinkTank } \\
\text { - } \quad \text { Speaker phone } \\
\text { - } \quad \text { Back line to David at ThinkTank. }\end{array}$ \\
\hline 30 & $\begin{array}{l}\text { E10:30 -11:00 } \\
\text { M8:30-9:00 } \\
\text { P 7:30-8:00 }\end{array}$ & $\begin{array}{l}\text { Networking, coffee, and logging on to ThinkTank. } \\
\text { Ensure connectivity and equipment functionality as per above. } \\
\text { Materials: Laptops and blue-slips. } \\
\text { Use this time to structure brief introductions. }\end{array}$ \\
\hline 30 & $\begin{array}{l}\text { E11:00-11:30 } \\
\text { M9:00-9:30 } \\
\text { P8:00-8:30 }\end{array}$ & $\begin{array}{l}\text { Simulcast plenary - senior DOE official. } \\
\text { GoToMeeting application. }\end{array}$ \\
\hline 20 & $\begin{array}{l}\text { E11:30-11:50 } \\
\text { M9:30-9:50 } \\
\text { P8:30-8:50 }\end{array}$ & First speaker via YouTube. \\
\hline
\end{tabular}




\begin{tabular}{|c|c|c|c|}
\hline 20 & $\begin{array}{l}\text { E11:50-12:10 } \\
\text { M9:50-10:10 } \\
\text { P8:50-9:10 }\end{array}$ & \multicolumn{2}{|c|}{$\begin{array}{l}\text { - Ground rules (ThinkTank will show these). } \\
\text { - Process and ThinkTank overview and tutorial. } \\
\text { [Facilitator can emphasize, "This is about idea generation }(80 \%) \text { and in small } \\
\text { part evaluating some of the ideas }(20 \%) \text {. What we won't do is spend time } \\
\text { evaluating the ideas that have been evaluated."] }\end{array}$} \\
\hline 15 & $\begin{array}{l}\text { E12:10-12:25 } \\
\text { M10:10-10:25 } \\
\text { P9:10-9:25 }\end{array}$ & \multicolumn{2}{|l|}{ BREAK } \\
\hline 45 & $\begin{array}{l}\text { E12:25-1:10 } \\
\text { M10:25-11:10 } \\
\text { P9:25-10:10 }\end{array}$ & $\begin{array}{l}\text { Focus Area 1: Use of Innovative Concepts } \\
\text { Question 1: "In the area of nuclear energy systems } \\
\text { and subsystems, where are the greatest opportunities } \\
\text { for innovation? Consider: what systems or components } \\
\text { don't exist today but, if they did, would substantially } \\
\text { change the field of nuclear energy? Be mindful of } \\
\text { regional implications or considerations." } \\
\text { - } \quad \text { Subject matter expert (SME) provides clarity and } \\
\text { examples } \\
\text { - } \quad \text { 70-points activity } \\
\text { - Provide clear and complete instructions-emphasize } \\
\quad \text { time constraints (2-minute exchanges with blue- } \\
\quad \text { slips) } \\
\text { - Blue slip-> Type it in->Process for Top } 3 \\
\text { - Submit Top } 3 \text { on ThinkTank. }\end{array}$ & $\begin{array}{l}\text { Prompt people to } \\
\text { keep their } \\
\text { exchanges brief. } \\
\text { Watch time, and } \\
\text { encourage people } \\
\text { to keep "moving." }\end{array}$ \\
\hline 20 & $\begin{array}{l}\text { E1:10-1:30 } \\
\text { M11:10-11:30 } \\
\text { P10:10-10:30 }\end{array}$ & \multicolumn{2}{|c|}{$\begin{array}{l}\text { Question } 2 \text { - For the innovation goals listed in the white paper (Affordable } \\
\text { electricity generation cost with emphasis on capital cost reduction; Better } \\
\text { integration with a dynamic grid with large input from renewable energy; } \\
\text { Enhanced safety and security; Reduced environmental impact; Reduced } \\
\text { proliferation risk; and Improved resource and waste management), rank the } \\
\text { goals in priority order that would benefit the most from innovative concepts. } \\
\text { - SME clarification if needed and RANKING on ThinkTank (make sure } \\
\text { people hit the "vote" button) } \\
\text { - Review ranking and discussion (10 minutes) } \\
\text { - } \quad \text { Re-vote if desired. }\end{array}$} \\
\hline 20 & $\begin{array}{l}\text { E1:30-1:50 } \\
\text { M11:30-11:50 } \\
\text { P10:30-10:50 }\end{array}$ & \multicolumn{2}{|l|}{ BREAK } \\
\hline
\end{tabular}




\begin{tabular}{|c|c|c|}
\hline 50 & $\begin{array}{l}\text { E1:50-2:40 } \\
\text { M11:50-12:40 } \\
\text { P10:50-11:40 }\end{array}$ & $\begin{array}{l}\text { Question 3: If the national nuclear R\&D programs (see the NE roadmap) are } \\
\text { not designed or configured to sufficiently foster innovative concepts, what } \\
\text { would be one thing you would do to strengthen or supplement the programs? } \\
\text { - } \quad \text { SME provides clarity and examples } \\
\text { - } \quad \text { 70-points activity } \\
\text { - } \quad \text { Blue slip-> Type it in->Process for Top } 3 \\
\text { - } \quad \text { Submit Top } 3 \text { on ThinkTank. }\end{array}$ \\
\hline 40 & $\begin{array}{l}\text { E2:40-3:20 } \\
\text { M12:40-1:20 } \\
\text { P11:40-12:20 }\end{array}$ & $\begin{array}{l}\text { Receive "All-Venue" results from ThinkTank. } \\
\text { Rate using ThinkTank to identify Top } 3 \text { per question: } \\
\text { - Question } 1 \text { - Most innovative; then feasibility, impact, and maturity } \\
\text { - Question } 2 \text { - Review and comment only } \\
\text { - Question } 3 \text { - Impact, then feasibility* and time to implement. } \\
\text { SME drafts "Key Themes" from this focus area (building toward concluding } \\
\text { summary report-out). } \\
\text { [Facilitator may want to advise the group, "When you're looking at the } \\
\text { combined lists, you will not have time to comment on every idea, so pick } \\
\text { the ones for which you have a lot of energy."] } \\
\text { Can combine some time from this segment with the following break (adds to } \\
\text { break time). } \\
\text { *Feasibility includes cost and risk (throughout this document). }\end{array}$ \\
\hline 10 & $\begin{array}{l}\text { E3:20-3:30 } \\
\text { M1:20-1:30 } \\
\text { P12:20-12:30 }\end{array}$ & BREAK \\
\hline 45 & $\begin{array}{l}\text { E3:30-4:15 } \\
\text { M1:30-2:15 } \\
\text { P12:30-1:15 }\end{array}$ & $\begin{array}{l}\text { Focus Area 2: Innovative Use of Existing Technologies } \\
\text { Question 1: What systems, subsystems, components or technologies exist in } \\
\text { other industries that, if adapted to nuclear energy, would make a significant } \\
\text { and favorable impact? Alternatively, what systems or technologies could } \\
\text { nuclear energy be adapted to in order to make a significant and favorable } \\
\text { impact? } \\
\text { - SME provides clarity and examples } \\
\text { - } \quad 70 \text {-points activity } \\
\text { - } \quad \text { Blue slip-> Type it in->Process for Top } 3 \\
\text { - Submit Top } 3 \text { on ThinkTank. }\end{array}$ \\
\hline
\end{tabular}




\begin{tabular}{|c|c|c|}
\hline 45 & $\begin{array}{l}\text { E4:15-5:00 } \\
\text { M2:15-3:00 } \\
\text { P1:15-2:00 }\end{array}$ & $\begin{array}{l}\text { Question 2: What are the biggest obstacles or unique challenges in adopting } \\
\text { some of the existing innovative technologies identified in Question } 1 \text { to } \\
\text { nuclear energy (e.g., nanotechnology, electronics, advanced M\&S, digital } \\
\text { instruments and controls)? } \\
\text { - SME provides clarity and examples } \\
\text { - Table discussion to identify } 1-3 \text { obstacles and HOW they could be } \\
\text { addressed } \\
\text { - Type in the example and proposed "solution" } \\
\text { - Direct each table to identify the example with the most impact (if } \\
\text { addressed), and present to the whole group } \\
\text { - Submit Top } 3 \text {. } \\
\text { EVENING Assignment: "Tomorrow we're going to respond to the question: } \\
\text { If we were starting with a clean sheet of paper with today's technologies, } \\
\text { what would the nuclear energy systems look like? Please be thinking about } \\
\text { that this evening. We'll be asking for your single biggest idea." } \\
\text { OPTIONAL discussion time if people want to stay and discuss ideas, etc. }\end{array}$ \\
\hline \multicolumn{3}{|r|}{$\begin{array}{c}\text { Day } 2 \\
\text { 6 Hours 15 Mins. (10:30 - 4:45 Eastern) }\end{array}$} \\
\hline 35 & $\begin{array}{l}\text { E10:30-11:05 } \\
\text { M8:30-9:05 } \\
\text { P7:30-8:05 }\end{array}$ & $\begin{array}{l}\text { Direct people to sit with different people today. } \\
\text { Log in } \\
\text { - } \quad \text { Second speaker via YouTube } \\
\text { - } \quad \text { Continue with Focus Area } 2 \text { questions. }\end{array}$ \\
\hline 30 & $\begin{array}{l}\text { E11:05-11:35 } \\
\text { M9:05-9:35 } \\
\text { P8:05-8:35 }\end{array}$ & $\begin{array}{l}\text { Question 3: For the innovation goals listed in the white paper (Affordable } \\
\text { electricity generation cost with emphasis on capital cost reduction; Better } \\
\text { integration with a dynamic grid with large input from renewable energy; } \\
\text { Enhanced safety and security; Reduced environmental impact; Reduced } \\
\text { proliferation risk; and Improved resource and waste management), identify } \\
\text { the top three in priority order that would benefit most from innovative use of } \\
\text { existing technologies. } \\
\text { - SME clarification if needed and RANKING on ThinkTank (make sure } \\
\text { people hit the "vote" button) } \\
\text { - Review ranking and discussion (10 minutes) } \\
\text { - Re-vote if desired. }\end{array}$ \\
\hline
\end{tabular}




\begin{tabular}{|c|c|c|}
\hline 40 & $\begin{array}{l}\text { E11:35-12:15 } \\
\text { M9:35-10:15 } \\
\text { P8:35-9:15 }\end{array}$ & $\begin{array}{l}\text { Question 4: If we were starting with a clean sheet of paper with today's } \\
\text { technologies, what would the nuclear energy systems look like? } \\
\text { - } \quad \text { SME clarification and examples } \\
\text { - } \quad \text { Blue-slip big idea; type it in } \\
\text { - } \quad \text { Pair-n-share; pair-n-pair by table } \\
\text { - } \quad \text { Decide on the "top" ideas among all tables (SME can give criteria or } \\
\text { basis) } \\
\text { - } \quad \text { Reform ideas (combine/revise wording) and re-type them in if reworded } \\
\text { - } \quad \text { Submit Top } 3 \text { to ThinkTank. }\end{array}$ \\
\hline 10 & $\begin{array}{l}\text { E12:15-12:25 } \\
\text { M10:15-10:25 } \\
\text { P9:15-9:25 }\end{array}$ & BREAK \\
\hline 45 & $\begin{array}{l}\text { E12:25-1:10 } \\
\text { M10:25-11:10 } \\
\text { P9:25-10:10 }\end{array}$ & $\begin{array}{l}\text { Receive "All-Venue" results from ThinkTank. } \\
\text { Rate using ThinkTank to identify Top } 3 \text { per question: } \\
\text { - Question } 1 \text { - Innovation; then adaptability, integration feasibility } \\
\text { - } \quad \text { Question } 2 \text { - Magnitude and safety margins } \\
\text { - Question } 3 \text { - Review and comment only } \\
\text { - Question } 4 \text { - Innovation; then feasibility. } \\
\text { SME drafts "Key Themes" from this focus area (building toward concluding } \\
\text { summary report-out). }\end{array}$ \\
\hline 25 & $\begin{array}{l}\text { E1:10-1:35 } \\
\text { M11:10-11:35 } \\
\text { P10:10-10:35 }\end{array}$ & $\begin{array}{l}\text { Focus Area 3: Innovative RD\&D Paradigm } \\
\text { Third speaker via YouTube. }\end{array}$ \\
\hline 20 & $\begin{array}{l}\text { E1:35-1:55 } \\
\text { M11:35-11:55 } \\
\text { P10:35-10:55 }\end{array}$ & BREAK \\
\hline 45 & $\begin{array}{l}\text { E1:55-2:40 } \\
\text { M11:55-12:40 } \\
\text { P10:55-11:40 }\end{array}$ & $\begin{array}{l}\text { Question 1: What are the one or two key attributes to an innovative } R \& D \\
\text { program that can reduce the cost and duration of the R\&D phase to (more } \\
\text { expediently) reach commercial readiness of (such) innovative concepts? } \\
\text { (R\&D phase is defined by the technology foundation and the input for design } \\
\text { and regulatory activities needed up to the construction of the first prototype.) } \\
\text { - } \quad \text { SME provides clarity and examples } \\
\text { - } \quad 70 \text {-points activity } \\
\text { - } \quad \text { Blue slip->Type it in->Process for Top } 3 \\
\text { - } \quad \text { Submit Top } 3 \text { on ThinkTank. }\end{array}$ \\
\hline
\end{tabular}




\begin{tabular}{|c|c|c|}
\hline 35 & $\begin{array}{l}\text { E2:40-3:15 } \\
\text { M12:40-1:15 } \\
\text { P11:40-12:15 }\end{array}$ & $\begin{array}{l}\text { Question 2: Provide an example of an innovative } R \& D \text { paradigm used by } \\
\text { other industries that nuclear energy } R \& D \text { could be modeled after. (See the } \\
\text { engineering-driven science-based approach defined in the NE roadmap.) } \\
\text { - } \quad \text { SME clarification and examples } \\
\text { - } \quad \text { Blue-slip big idea (what and why) and type it in } \\
\text { - } \quad \text { Pair-n-share; pair-n-pair } \\
\text { - } \quad \text { Decide on the "top" ideas (SME can give criteria or basis ) } \\
\text { - } \quad \text { Submit Top } 3 \text { to ThinkTank. }\end{array}$ \\
\hline 10 & $\begin{array}{l}\text { E3:15-3:25 } \\
\text { M1:15-1:25 } \\
\text { P12:15-12:25 }\end{array}$ & BREAK \\
\hline 45 & $\begin{array}{l}\text { E3:25-4:10 } \\
\text { M1:25-2:10 } \\
\text { P12:25-1:10 }\end{array}$ & $\begin{array}{l}\text { Question 3: What are one or two infrastructure gaps (physical and } \\
\text { intellectual) within the U.S. that, if filled, would allow for the adoption of a } \\
\text { faster and cheaper R\&D paradigm - or how could existing infrastructure be } \\
\text { differently utilized for this purpose? } \\
\text { - SME provides clarity and examples } \\
\text { - Table discussion to identify 1-3 key gaps and HOW they could be } \\
\text { addressed } \\
\text { - Type in the example and proposed "solution" } \\
\text { - } \quad \text { Direct each table to identify the example with the most impact (if } \\
\text { - } \quad \text { Submit Top 3. }\end{array}$ \\
\hline 35 & $\begin{array}{l}\text { E4:10-4:45 } \\
\text { M2:10-2:45 } \\
\text { P1:10-1:45 }\end{array}$ & $\begin{array}{l}\text { Question 4: For the innovation goals listed in the white paper (Affordable } \\
\text { electricity generation cost with emphasis on capital cost reduction; Better } \\
\text { integration with a dynamic grid with large input from renewable energy; } \\
\text { Enhanced safety and security; Reduced environmental impact; Reduced } \\
\text { proliferation risk; and Improved resource and waste management), identify } \\
\text { the three in priority order that would benefit the most from a faster and } \\
\text { cheaper R\&D paradigm. } \\
\text { - SME clarification if needed and RANKING on ThinkTank (make sure } \\
\text { people hit the "vote" button) } \\
\text { - Review ranking and discussion (10 minutes) } \\
\text { - Re-vote if desired. } \\
\text { OPTIONAL discussion time if people want to stay and discuss ideas, etc. }\end{array}$ \\
\hline
\end{tabular}




\begin{tabular}{|c|c|c|}
\hline \multicolumn{3}{|r|}{$\begin{array}{c}\text { Day } \mathbf{3} \\
7 \text { Hours }(10: 30-5: 30 \text { Eastern }) \\
\end{array}$} \\
\hline 45 & $\begin{array}{l}\text { E10:30-11:15 } \\
\text { M8:30-9:15 } \\
\text { P7:30-8:15 }\end{array}$ & $\begin{array}{l}\text { Have people sit with different people. } \\
\text { Receive "All-Venue" results from ThinkTank. } \\
\text { Rate using ThinkTank to identify Top } 3 \text { per question: } \\
\text { - } \quad \text { Question } 1 \text { - Impact on time reduction; then cost reduction and risk } \\
\text { - } \quad \text { Question } 2 \text { - Innovation; then adaptability and regulatory constraint level } \\
\text { - Question } 3 \text { - Magnitude (size); then ease of implementation } \\
\text { - } \quad \text { Question } 4 \text { - Review and comment only. } \\
\text { SME drafts "Key Themes" from this focus area (building toward concluding } \\
\text { summary report-out). }\end{array}$ \\
\hline 25 & $\begin{array}{l}\text { E11:15-11:40 } \\
\text { M9:15-9:40 } \\
\text { P8:15-8:40 }\end{array}$ & $\begin{array}{l}\text { Focus Area 4: Innovative Licensing Paradigm } \\
\text { Fourth speaker via YouTube. }\end{array}$ \\
\hline 45 & $\begin{array}{l}\text { E11:40-12:25 } \\
\text { M9:40-10:25 } \\
\text { P8:40-9:25 }\end{array}$ & $\begin{array}{l}\text { Question 1: What do we need to change (if anything) in the licensing } \\
\text { paradigm to achieve commercial readiness of innovative concepts faster than } \\
\text { the current paradigm allows? (This question focuses on technical areas such } \\
\text { as safety basis, design requirements, etc., and not the regulatory process } \\
\text { issues.) } \\
\text { - SME provides clarity and examples } \\
\text { - Table discussion to identify } 1-3 \text { aspects to change and HOW they could } \\
\text { be addressed } \\
\text { - Type in the changes and proposed "solutions" or how to affect the } \\
\text { change(s) } \\
\text { - Direct each table to identify the change with the most impact (if } \\
\text { addressed, and present to the whole group } \\
\text { - Submit Top } 3 \text {. }\end{array}$ \\
\hline 10 & $\begin{array}{l}\text { E12:25-12:35 } \\
\text { M10:25-10:35 } \\
\text { P9:25-9:35 }\end{array}$ & BREAK \\
\hline 35 & $\begin{array}{l}\text { E12:35-1:10 } \\
\text { M10:35-11:10 } \\
\text { P9:35-10:10 }\end{array}$ & $\begin{array}{l}\text { Question 2: To make the current approaches to development of regulatory } \\
\text { safety criteria and design requirements compatible with the R\&D paradigm } \\
\text { you identified in Focus Area 3, Q.2., what would you have to change? } \\
\text { - } \quad \text { SME clarification and examples } \\
\text { - } \quad \text { Blue-slip big idea } \\
\text { - } \quad \text { Pair-n-share; pair-n-pair } \\
\text { - } \quad \text { Decide on the "top" ideas (SME can give criteria or basis ) } \\
\text { - } \quad \text { Submit Top } 3 \text { to ThinkTank. }\end{array}$ \\
\hline
\end{tabular}




\begin{tabular}{|c|c|c|}
\hline 45 & $\begin{array}{l}\text { E1:10-1:55 } \\
\text { M11:10-11:55 } \\
\text { P10:10-10:55 }\end{array}$ & $\begin{array}{l}\text { Question 3: List any regulatory examples of other industries that can enable } \\
\text { faster innovation. } \\
\text { - } \quad \text { SME provides clarity and examples } \\
\text { - } \quad \text { Table discussion to identify } 1-3 \text { examples and the benefits of each } \\
\text { - } \quad \text { Type in the example and benefits } \\
\text { - } \quad \text { Direct each table to identify the examples with the most benefits and } \\
\text { - } \quad \text { Submit Top } 3 \text { most beneficial. }\end{array}$ \\
\hline 35 & $\begin{array}{l}\text { E1:55-2:30 } \\
\text { M11:55-12:30 } \\
\text { P10:55-11:30 }\end{array}$ & $\begin{array}{l}\text { Question 4: For the innovation goals listed in the white paper (Affordable } \\
\text { electricity generation cost with emphasis on capital cost reduction; Better } \\
\text { integration with a dynamic grid with large input from renewable energy; } \\
\text { Enhanced safety and security; Reduced environmental impact; Reduced } \\
\text { proliferation risk; and Improved resource and waste management), identify } \\
\text { the top three in priority order that would benefit the most from innovation in } \\
\text { the licensing paradigm. } \\
\text { - SME clarification if needed and RANKING on ThinkTank (make sure } \\
\text { people hit the "vote" button) } \\
\text { - Review ranking and discussion (10 minutes) } \\
\text { - Re-vote if desired. }\end{array}$ \\
\hline 20 & $\begin{array}{l}\text { E2:30-2:50 } \\
\text { M12:30-12:50 } \\
\text { P11:30-11:50 }\end{array}$ & BREAK \\
\hline 50 & $\begin{array}{l}\text { E2:50-3:35 } \\
\text { M12:50-1:35 } \\
\text { P11:50-12:35 }\end{array}$ & $\begin{array}{l}\text { Receive "All-Venue" results from ThinkTank. } \\
\text { Rate using ThinkTank to identify Top } 3 \text { per question: } \\
\text { - Question } 1 \text { - Feasibility; then impact on time reduction } \\
\text { - Question } 2 \text { - Adaptability and regulatory constraint level } \\
\text { - Question } 3 \text { - Adaptability, then clarity of benefit to nuclear industry and } \\
\text { - } \quad \text { Question } 4 \text { - Review and comment only. } \\
\text { SME drafts "Key Themes" from this focus area (building toward concluding } \\
\text { summary report-out). }\end{array}$ \\
\hline 10 & $\begin{array}{l}\text { E3:35-3:45 } \\
\text { M1:35-1:45 } \\
\text { P12:35-12:45 }\end{array}$ & BREAK \\
\hline
\end{tabular}




\begin{tabular}{|c|l|l|l|}
\hline 25 & $\begin{array}{l}\text { E3:45-4:10 } \\
\text { M1:45-2:10 } \\
\text { P12:45-1:10 }\end{array}$ & $\begin{array}{l}\text { SUMMARY SESSION } \\
\text { The groups will revisit their themes for each focus area and identify those } \\
\text { ideas that have a regional connection. } \\
\text { These products will be submitted to ThinkTank and included in the venue's } \\
\text { regional report-out. }\end{array}$ & $\begin{array}{l}\text { Template } \\
\text { ThinkTank and } \\
\text { speaker phone }\end{array}$ \\
\hline 70 & $\begin{array}{l}\text { E4:10-5:20 } \\
\text { M2:10-3:20 } \\
\text { P1:10-2:20 }\end{array}$ & $\begin{array}{l}\text { Regional Report-Outs } \\
\text { Selected spokesman presents focus area key themes } \\
\text { and regional implications. }\end{array}$ \\
\hline 10 & $\begin{array}{l}\text { E5:20-5:30 } \\
\text { M3:20-3:30 } \\
\text { P2:20-2:30 }\end{array}$ & $\begin{array}{l}\text { Closing Remarks - Sr. DOE Official via GoToMeeting. } \\
\text { Adjournment }\end{array}$ \\
\hline
\end{tabular}




\section{APPENDIX C.}

\section{WORKSHOP FOCUS AREAS AND OUTPUT}

The original output data from the six workshops are far too extensive and unfocused to include in this report in their raw form. They have been processed using the ThinkTank software in order to group similar ideas under category names that attempt to capture the similar themes. Some of the underlying commentary is included here where necessary to strengthen or define specific summarizations. The original questions that were posed to workshop participants are included here along with the summaries of results. As described above, the workshop was broken up into four focus areas, in which several questions were posed, and then responses were ranked by the entire group against specific ranking criteria.

As noted in the introduction for this report, the workshop participants represented a very diverse cross section of backgrounds and focus areas. Summaries are captured in bulleted lists that represent combinations of top-rated ideas, because many naturally belonged together. In some places, ideas are known to be already addressed or misguided by lack of familiarity, so notes of clarification are added. Additionally, it is noted that there were four questions related to the benefit to the six innovation goals if innovations in the four focus areas were realized. Voting results seem to indicate that there was confusion regarding these ranking questions; consequently, the results are not included in this final report. For those with an interest in results of these rankings, the raw data may be obtained as indicated below.

Raw data are archived and available on the workshop website (https://nuclearinnovationworkshop.inl.gov/SitePages/Home.aspx) or by request. To request original output data, the reader should contact the Idaho National Laboratory (http://www.inl.gov) Communications Department and request Document Number INL/MIS-15-36465.

\section{C.1 Definitions of Voting Criteria}

Participants were asked to rank output from several of the questions. In order to do so, definitions for use during these workshops were provided for consistency. These definitions are:

Innovation - Implementation of an idea or technology, or use of a technology, that is distinctly different from historical record.

Feasibility - Realistically achievable, primarily with respect to technical complexity (i.e., doesn't break the laws of physics or rely on unproven phenomenon) but also with respect to cost, predictability, and risk. Generally, extremely high technical complexity, high cost, low predictability, or high risk (see definition below) would drive feasibility rankings lower.

Impact - The degree to which a concept can be considered "disruptive."

Maturity - The current level of understanding or development: Are we starting from the ground up, or has the technology just not been implemented in this way?

Adaptability - Ease of integration in transitioning from one industry to another. Is this something that simply requires a technology to be developed for transition, or does it include other far-reaching modifications such as fundamental changes in underlying physics, sweeping policy changes, etc?

Magnitude - The perceived size of an obstacle with respect to our ability to overcome it.

Safety margins - Size of the gap that would exist if a technology were transitioned from other industries to the nuclear industry in terms of overall safety of the system. 
Risk (in most cases combined with feasibility) - The likelihood that failure of the proposed program or technology would create large loss (financial, life, capital).

Regulatory constraint level - The perceived level of interaction that would be required with a regulatory agency (U.S. Nuclear Regulatory Commission [NRC]) if the proposed idea were implemented.

\section{C.2 Summarized Output From Main Workshops}

\section{C.2.1 Focus Area 1: Use of Innovative Concepts}

\section{C.2.1.1 FA1, Question 1}

"In the area of nuclear energy systems and subsystems, where are the greatest opportunities for innovation? Consider what systems or components don't exist today but, if they did, would substantially change the field of nuclear energy? Be mindful of regional implications or considerations."

Top response summaries as voted against innovation, feasibility, impact, and maturity criteria:

- $\quad$ R\&D into improving the designs of fuels and cladding for improved fuel performance, increased safety margin, and ease of recycling.

- Improvement of full fuel cycle management and radioactive waste management.

- Early education programs and interfacing with the public for enhanced understanding and awareness of nuclear energy.

- R\&D into decreasing the costs of construction. Primarily this is understood to be in the ability to modularize construction. The goal is to reach an "off the shelf" product availability.

- Development of secure wireless instrument and control systems.

- Development of test and demonstration reactors to further development of concepts: reconfigurable, fast and thermal neutron spectrum, capable of concept demonstration, and test safety aspects.

- Develop innovative energy conversion systems and alternative reactor uses: research load following, Brayton cycles, hybrid systems, nuclear-paired heat storage options, and direct-nuclear-to-electricheat conversion systems.

\section{C.2.1.2 FA1, Question 2}

"For the innovation goals listed in the white paper (Affordable electricity generation cost with emphasis on capital cost reduction; Better integration with a dynamic grid with large input from renewable energy; Enhanced safety and security; Reduced environmental impact; Reduced proliferation risk; and Improved resource and waste management), rank the goals in priority order that would benefit the most from innovative concepts."

The ranking results from this question are not included in the final report because of confusion surrounding the ranking process, but they are included in the raw data available on the Nuclear Innovation website (https://nuclearinnovationworkshop.inl.gov/SitePages/Home.aspx).

\section{C.2.1.3 FA1, Question 3}

"If the national nuclear R\&D programs (see the NE roadmap) are not designed or configured to sufficiently foster innovative concepts, what would be one thing you would do to strengthen or supplement the programs?"

Top response summaries as voted against impact and feasibility criteria, as well as perceived time to implement: 
- An improved R\&D funding model that is more stable (includes fully funded science-to-demonstration activities and promotes international collaboration).

- Infrastructure improvements, including a versatile national test reactor.

- A fast spectrum test reactor is needed to supplement existing mixed spectrum test reactors.

- Access to critical R\&D infrastructure by the research community.

- Note: The U.S. Department of Energy (DOE), Office of Nuclear Energy does have user facilities that offer access to hot cells, test reactors, and post-irradiation examination equipment (i.e., the Nuclear Science User Facilities).

- Improved licensing framework that allows rapid development and deployment of prototype reactors.

- Note: Most of this framework exists; the challenge is to understand the limits and utility of this framework.

- A consistent national energy policy that has a focused and staged strategy to foster development of real, practical nuclear reactor technology.

- Integration of R\&D and management, including development of a national test bed and development and demonstration facility with potential oversight by a collaborative council consisting of members from industry, national laboratories, and academia.

\section{C.2.2 Focus Area 2: Innovative Use of Existing Technologies}

\section{C.2.2.1 FA2, Question 1}

"What systems, subsystems, components, or technologies exist in other industries that, if adapted to nuclear energy, would make a significant and favorable impact? Alternatively, what systems or technologies could nuclear energy be adapted to in order to make a significant and favorable impact?"

Top response summaries as voted against innovation, adaptability, and integration feasibility criteria:

- Re-purposing nuclear reactors for other uses such as radioisotope production, desalination of water, hydrogen, or process heat.

- Materials processing for efficient construction, enhanced safety, and enhanced lifetimes.

- Advanced instrumentation for plant feedback and control in support of safety or degradation mitigation.

- Adaptation of nuclear reactor energy transfer and storage systems to enhance efficiency or allow expanded usage.

- Process and policy adaptation such as use of siting strategies and quality assurance standards with learnings from other industries.

\section{C.2.2.2 FA2, Question 2}

"What are the biggest obstacles or unique challenges in adopting some of the existing innovative technologies identified in Question 1 to nuclear energy (e.g., nanotechnology, electronics, advanced $M \& S$, digital $I \& C)$ ?

Top response summaries as voted against magnitude and safety margins criteria:

- Risk-averse policy and regulation.

- Note: Some risk aversion may be a byproduct of the funding model employed by NRC, whereby a majority of funding is obtained from licensees. 
- Adaptation of codes and standards from one industry to another and required improvement in development of standards for modern application.

- Uncertainty in the level of economic risk associated with implementation of innovative concepts.

- Social issues involving the need for security and demographics of technical professionals.

- Funding and focus issues at the federal level.

\section{C.2.2.3 FA2, Question 3}

"For the innovation goals listed in the white paper (Affordable electricity generation cost with emphasis on capital cost reduction; Better integration with a dynamic grid with large input from renewable energy; Enhanced safety and security; Reduced environmental impact; Reduced proliferation risk; and Improved resource and waste management), identify the top three in priority order that would benefit most from innovative use of existing technologies."

The ranking results from this question are not included in the final report because of confusion surrounding the ranking process, but they are included in the raw data available on the Nuclear Innovation website (https://nuclearinnovationworkshop.inl.gov/SitePages/Home.aspx).

\section{C.2.2.4 FA2, Question 4}

"If we were starting with a clean sheet of paper with today's technologies, what would the nuclear energy systems look like? “

Top response summaries as voted against innovation and feasibility criteria:

- High-temperature reactors to enhance conversion efficiency (probably getting away from water) and reduce fuel consumption.

- Closed fuel cycles and inherently safe design.

- Scalable and modular reactors that include a mix of thermal and fast-spectrum technologies that are standardized and utilize real time or smart diagnostic systems.

- Clear national policy for nuclear with a long-term plan and a regulatory approach that supports this policy.

- Reactor and fuel cycle designs that are driven by waste minimization and efficiency.

- Plants that are designed and sited to take advantage of power needs or unique geographical characteristics.

\section{C.2.3 Focus Area 3: Innovative RD\&D Paradigm}

\section{C.2.3.1 FA3, Question 1}

"What are the one or two key attributes to an innovative $R \& D$ program that can reduce the cost and duration of the $R \& D$ phase to (more expediently) reach commercial readiness of (such) innovative concepts? (R\&D phase is defined by the technology foundation and the input for design and regulatory activities needed up to the construction of the first prototype.)"

Top response summaries as voted against impact on time reduction, cost reduction, and level of perceived risk:

- A realistic, implementable U.S. energy policy with sustained funding for the R\&D needed to accomplish it. 
- Applied engineering facilities for testing bench-scale to full-reactor concepts that are required for nuclear energy R\&D. These facilities need to have a dedicated, knowledgeable staff and be open to all.

- Independent oversight for $\mathrm{R} \& \mathrm{D}$, including the use of the testing facilities.

- Funding for basic, applied, bench-scale, prototype, and full-scale testing. Funding should be sustained for nationally accepted concepts but also be available for specific grand challenges and exploring innovative concepts. Funding may go from a single investigator to large consortia.

- Versatile, open test beds with dedicated, knowledgeable staff to assist in the R\&D.

- New funding paradigms to include, high risk-high reward plans, an agreed upon Grand Challenge, and funding for centralized innovation hubs.

\section{C.2.3.2 FA3, Question 2}

"Provide an example of an innovative $R \& D$ paradigm used by other industries that nuclear energy $R \& D$ could be modeled after. (See the engineering-driven science-based approach defined in the NE roadmap.)"

Top response summaries as voted against impact on innovation, adaptability, and regulatory constraint level criteria:

- Industry R\&D paradigms, including those employed by the pharmaceutical industry, the video gaming industry, Proctor \& Gamble, the XPRIZE/Gates Foundation, and the North East Oil Heat Research Alliance.

- Note: These R\&D paradigms tend to have very clearly defined goals and involve alignment of industry and researcher interests, including competitive parallel design schemes.

- Non-industrial R\&D paradigms, including Naval Reactors, the Defense Advanced Research Projects Agency, NASA, the National Energy Technology Laboratory.

- Note: These R\&D paradigms tend to feature extended, disciplined approaches toward a welldefined goal.

- Other R\&D paradigms suggested that may not be examples of existing paradigms, including public engagement in R\&D, clear stakeholder involvement, gated approaches, and integral design schemes.

\section{C.2.3.3 FA3, Question 3}

"What are one or two infrastructure gaps (physical and intellectual) within the U.S. that, if filled, would allow for the adoption of a faster and cheaper R\&D paradigm - or how could existing infrastructure be differently utilized for this purpose? "

Top response summaries as voted against magnitude as a criterion as well as ease of implementation:

- Scalable, easily reconfigurable bench- to full-scale test facilities utilizing a user facility model for access spanning the breadth of nuclear testing needs: materials to full-scale reactors to fuel cycle. This includes appropriate modeling and simulation capacity.

- Note: The DOE Office of Nuclear Energy does have user facilities that offer open access, i.e., the Nuclear Science User Facilities.

- Education support: Modernize and enhance the K-University STEM curriculums, including nuclear engineering and other supporting sciences. Make sure to include necessary soft skills such as critical thinking, writing, and speaking. Provide for internship opportunities to develop real-world experience.

- Improved knowledge preservation, management, and transfer mechanisms. 
- Ability of the NRC to conduct the reviews of the new reactor designs - either through funding for staff or funding for appropriate R\&D.

\section{C.2.3.4 FA3, Question 4}

"For the innovation goals listed in the white paper (Affordable electricity generation cost with emphasis on capital cost reduction; Better integration with a dynamic grid with large input from renewable energy; Enhanced safety and security; Reduced environmental impact; Reduced proliferation risk; and Improved resource and waste management), identify the three in priority order that would benefit the most from a faster and cheaper $R \& D$ paradigm. "

The ranking results from this question are not included in the final report because of confusion surrounding the ranking process, but they are included in the raw data available on the Nuclear Innovation website (https://nuclearinnovationworkshop.inl.gov/SitePages/Home.aspx).

\section{C.2.4 Focus Area 4: Innovative Licensing Paradigm}

\section{C.2.4.1 FA4, Question 1}

"What do we need to change (if anything) in the licensing paradigm to achieve commercial readiness of innovative concepts faster than the current paradigm allows? (This question focuses on technical areas such as safety basis, design requirements, etc., and not the regulatory process issues.) "

Top response summaries as voted against feasibility as a criterion as well as impact on time reduction:

- An improved NRC funding model to allow more public funding to be used, allowing additional attention to be paid to advanced reactor licensing.

- Development of an alternative regulatory framework that includes the following:

- Risk-informed regulation.

- Note: NRC already utilizes risk-informed decision-making to a certain extent.

- A third-party technical consulting entity that engages with designers with a regulatory perspective but is firewalled from NRC in order to generate "regulatory pull" similar to market pull.

- Defined incremental licensing milestones for easily tracked progress rather than holistic licensing.

- A "demonstration license" for prototyping.

- Note: DOE already has this authority to a certain extent.

- A regulatory approach and policy adapted to encourage innovation, as follows:

- Design specific regulations that incorporate beta testing of licensing processes.

- Remove prescriptive limits that apply to only specific systems.

$\circ \quad$ Use staged and incremental licensing processes.

- Re-charter the NRC to focus on combined safety, time to market, operability, innovation, national security, and then the process to quickly incorporate learning to change regulatory requirements. Add in accountability to a board of directors composed of stakeholders and adherence to a national nuclear policy. Maintain their independence, but add in metrics and incentives for accelerating innovation similar to the Food and Drug Administration).

- Create and implement a set of technology-neutral regulatory criteria. 


\section{C.2.4.2 FA4, Question 2}

"To make the current approaches to development of regulatory safety criteria and design requirements compatible with the $R \& D$ paradigm you identified in Focus Area 3, Q.2., what would you have to change? "

This question was discarded by the overall technical subject matter expert during the workshop because of confusion among participants and was thus not addressed.

\section{C.2.4.3 FA4, Question 3}

"List any regulatory examples of other industries that can enable faster innovation. "

Top response summaries as voted against adaptability and regulatory constraint level as a criteria, as well as clarity of benefit to the nuclear industry:

- The aerospace industry with the Federal Aviation Administration.

- Jet engine regulation involves step-by-step involvement in design and production by the regulator.

- Department of Defense prototype engine acceptance.

- The pharmaceutical/medical industry.

- The Food and Drug Administration is involved in early drug development and has a staged regulatory process.

- The automobile industry.

- The regulatory process for the automobile is performance-based and involves safety testing that enhances public confidence.

- Communications/media.

- The communications industry has a very different risk level but does deal with extreme growth.

\section{C.2.4.4 FA4, Question 4}

"For the innovation goals listed in the white paper (Affordable electricity generation cost with emphasis on capital cost reduction; Better integration with a dynamic grid with large input from renewable energy; Enhanced safety and security; Reduced environmental impact; Reduced proliferation risk; and Improved resource and waste management), identify the top three in priority order that would benefit the most from innovation in the licensing paradigm. "

The ranking results from this question are not included in the final report because of confusion surrounding the ranking process, but they are included in the raw data available on the Nuclear Innovation website (https://nuclearinnovationworkshop.inl.gov/SitePages/Home.aspx).

\section{C.3 Summarized Output from Advanced Manufacturing \& Supply Chain Conference Mini-Session}

Several weeks after the Nuclear Innovation Workshops were conducted, an Advanced Manufacturing \& Supply Chain conference sponsored by Premier Technologies in association with several others was held in Pocatello, Idaho. A number of individuals participating in this conference were requested to take part in a break-out session to address innovation in manufacturing, the results of which would be used to add to the output from the Nuclear Innovation Workshops. Participants were posed three questions and were asked to rank ideas formulated by the group. A summary of these ideas is included here. 


\section{C.3.1 Advanced Manufacturing Breakout Question 1}

"New Manufacturing Technologies: what technology is currently working in other industries that can be applied to nuclear?"

- Advanced manufacturing processes.

- Hot isostatic press processes to produce large forgings.

- Advanced joining techniques, including laser- or electron-beam-assisted, friction-stir, and inertial welding.

- Powder metallurgy and hot isostatic press-fabricated materials.

- Post-process treatments to extend durability through resistance to degradation mechanisms, such as laser or water-jet peening.

- Large-scale additive manufacturing.

- Computational tools that have been properly validated.

- Integrated system fabrication analytics.

- Virtually-reality-facilitated design development/modeling and testing.

- Computer numerical control used for advanced welding/joining.

\section{C.3.2 Advanced Manufacturing Breakout Question 2}

"Process Design, Engineering, and Efficiency: What can be changed to improve the efficiency and repeatability of the current design and engineering phase of nuclear builds-to better facilitate deployment? “

- Improved communication between all phases (procurement, design, building, deployment, operation, decommissioning).

- Feedback loops between each phase to ensure continuous improvement in designs and execution of manufacturing processes and to ensure that intensive phases like decommissioning are not cost prohibitive due to unplanned expenses.

- Inclusion of a larger sector in the qualification, training, and understanding of manufacturing to foster a larger supply chain base and a broader population of trained workers to execute production steps.

- Multi-scale modeling that is informed by field experience (probabilistic characterization of component response, normal and off-normal operating conditions, control system vulnerability).

- Validation and acceptance through modeling and simulation based not only on experimental data but on the field experience data and associated informatics.

\section{C.3.3 Advanced Manufacturing Breakout Question 3}

"Streamlined Processes: What can be changed to improve the current response time between contracted partners through the supply chain?"

- Ability for customers to review products before full-scale production begins.

- Prototyping, small-scale production runs that can be appropriately ramped up to efficient production processes.

- Modeling and simulation output that interfaces with standard production software and can be tailored to effectively interrogate appropriate suppliers that have available production time who in turn can provide "born-qualified" components and systems. 


\section{Nuclear Innovation Workshops}

- Standardized process and quality requirements.

- Also, standardized intellectual property agreements. 